\title{
Spontaneous Intracranial Hypotension in the Absence of Magnetic Resonance Imaging Abnormalities
}

\author{
Kerrie L. Schoffer, Timothy J. Benstead, Ian Grant
}

\begin{abstract}
Background: Spontaneous intracranial hypotension (SIH) is a neurologic syndrome of unknown etiology, characterized by features of low cerebral spinal fluid (CSF) pressure, postural headache and magnetic resonance imaging (MRI) abnormalities. Methods: Four symptomatic cases of SIH presented to our institution over a six-month period. Magnetic resonance imaging studies were performed in all four cases. Diagnostic lumbar puncture was done in all except one case. Results: All of the patients on whom lumbar punctures were performed demonstrated low CSF pressure and CSF protein elevation with negative cultures and cytology. Three out of the four patients exhibited MRI findings of diffuse spinal and intracranial pachymeningeal gadolinium enhancement and extradural or subdural fluid collections. One patient had no MRI abnormalities despite prominent postural headache and reduced CSF pressure at lumbar puncture. All patients recovered with intravenous fluids and conservative treatment. Conclusions: Magnetic resonance imaging abnormalities are found in most, but not all patients, with SIH. Cerebral spinal fluid abnormalities can be detected even in patients with normal MRI studies. It is important to recognize the variability of imaging results in this usually benign disorder.
\end{abstract}

RÉSUMÉ: Hypotension intracrânienne spontanée sans anomalie à l'imagerie par résonance magnétique. Introduction: L'hypotension intracrânienne spontanée (HIS) est un syndrome neurologique d'étiologie inconnue, caractérisé par des manifestations d'une pression basse du liquide cérébro-rachidien (LCR), de céphalée posturale et d'anomalies à l'imagerie par résonance magnétique (IRM). Méthodes: Quatre patients présentant des symptômes d'HIS ont été évalués dans notre institution sur une période de six mois. Des études d'IRM ont été effectuées dans les quatre cas et une ponction lombaire diagnostique a été faite chez trois d'entre eux. Résultats: Tous les patients qui ont subi une ponction lombaire avaient une pression du LCR qui était basse et une élévation des protéines avec culture et cytologie négatives. À l'IRM, trois des quatre patients avaient des signes diffus de rehaussement pachyméningé spinal et intracrânien au gadolinium, et des collections de liquide extraduraux ou sous-duraux. Un patient présentait une IRM normale malgré une céphalée posturale marquée et une pression basse du LCR à la ponction lombaire. Tous les patients ont récupéré avec une hydratation parentérale et un traitement conservateur. Conclusions: On trouve des anomalies à l'IRM chez la plupart des patients présentant une HIS. Des anomalies du LCR peuvent être présentes même chez les patients dont l'IRM est normale. Il est important de connaître la variabilité observée à l'imagerie dans ce désordre habituellement bénin.

Can. J. Neurol. Sci. 2002; 29: 253-257

Originally named "aliquorrhea" by Schaltenbrand" in 1938 , spontaneous intracranial hypotension (SIH) is an increasingly recognized syndrome characterized by a triad of low CSF pressure, postural headache, and magnetic resonance imaging (MRI) abnormalities. ${ }^{2}$ The classic MRI finding of diffuse pachymeningeal enhancement, ${ }^{3}$ with leptomeningeal sparing, is thought to be a result of engorgement of dural bridging veins secondary to decreased CSF pressure. ${ }^{4}$ This is such a hallmark feature that its absence has been suggested to exclude the diagnosis. ${ }^{2}$ There have been only a few reported cases of SIH with absent MRI findings. ${ }^{5}$

We report four cases of SIH that presented to our institution within a period of six months. Three of the cases exhibited classic MRI changes of SIH. The fourth case, despite typical symptomatology and low CSF pressure, demonstrated no MRI abnormalities.

\footnotetext{
From the Division of Neurology, Dalhousie University, Halifax, NS Canada ReCEIVED OCTOBER 18, 2001. ACCEPTED IN FINAL FORM MARCH 26, 2002. Reprint requests to: Timothy J. Benstead, QE II Health Sciences Centre, 1796 Summer St., Halifax, Nova Scotia B3H 3A7 Canada
} 


\section{Case Illustrations}

\section{Patient 1}

A 36-year-old previously healthy female presented with sudden, spontaneous headache of three weeks duration, worse in sitting position and relieved lying down. She had no relief with ibuprofen. Photophobia, phonophobia, and fever were absent. Neurological examination was normal. Screening blood work was normal. Lumbar puncture showed no CSF red blood cells, $890 \mathrm{mg} / \mathrm{L}$ protein (normal range is $150-450 \mathrm{mg} / \mathrm{L}$ ), and 3 white blood cells (WBC) $/ \mathrm{mm}^{3}$. Fluid flowed too slowly to measure a pressure. Cerebral spinal fluid culture was negative. Magnetic resonance imaging showed evidence of subdural fluid in the upper cervical region and diffuse pachymeningeal enhancement (Figure 1). The cerebellar tonsils were low-lying. She was treated conservatively with intravenous hydration and bedrest, with complete resolution of symptoms over several weeks.

\section{Patient 2}

A 47-year-old diabetic female with a history of ischemic heart disease was admitted with a three week history of postural headache. Accompanying symptoms included a ten-pound weight loss, facial tingling, and mild ataxia. The patient had started a new yoga program and had been on a roller coaster ride that preceeded the onset of symptoms. The headache was unresponsive to meperidine. Neurological exam revealed only mild difficulty with tandem gait. No lumbar puncture was performed. An MRI study showed diffuse pachymeningeal enhancement, subdural fluid from C1-T1 anteriorly (Figure 2), and brainstem descent. The headache resolved within a week with administration of intravenous fluids.

\section{Patient 3}

A 49-year-old female with a history of hypertension and hypothyroidism awoke from sleep, one week prior to admission, with sudden severe neck and head pain, nausea, and vomiting. The

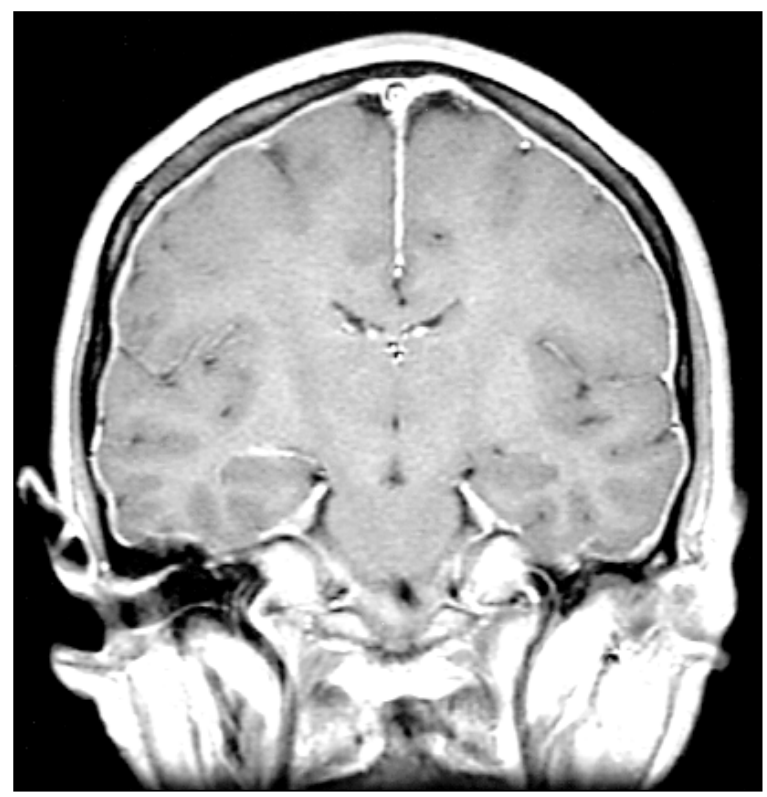

Figure 1: Gadolinium-enhanced coronal MRI showing diffuse pachymeningeal enhancement characteristic of SIH (Patient 1)

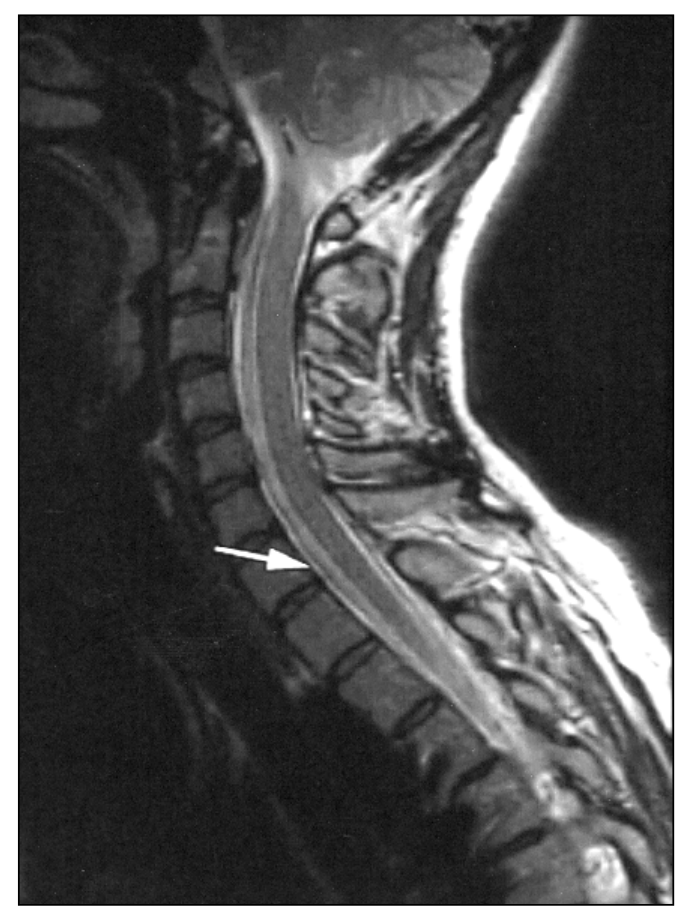

Figure 2: Sagittal T1 weighted MRI of the cervical spine demonstrating subdural fluid collection from C1-T1 (Patient 2)

holocranial headache was relieved in a recumbent position. Neurological exam was normal except for neck tenderness. CSF revealed a $1630 \mathrm{mg} / \mathrm{L}$ of protein, normal glucose, $4 \mathrm{WBC} / \mathrm{mm}^{3}$ and no red blood cells. CSF cultures and cytology were negative. CSF pressure was less than $30 \mathrm{~mm}$ $\mathrm{H}_{2} \mathrm{O}$ (normal levels should be 100-200 $\mathrm{mm} \mathrm{H}_{2} \mathrm{O}$ ), computerized tomography (CT) scanning and cerebral angiography were negative. Magnetic resonance imagin showed diffuse pachymeningeal enhancement, extradural fluid from $\mathrm{C} 1-3$ and an enhancing lesion in the head of the right caudate (Figure 3). Due to the caudate lesion, rheumatology and endocrinology screens were done and found to be within normal limits. A bone scan and a gallium scan to rule out lymphoma were negative. Chest/abdomen/ pelvis CT was negative. She was treated with intravenous hydration and bedrest. Repeat MRI several months later when patient was asymptomatic showed complete resolution of both the meningeal enhancement and the caudate lesion.

\section{Patient 4}

A 37-year-old male with a history of childhood retinoblastoma and encephalitis (with no neurological sequelae) presented with a three day history of stabbing headache behind his left eye radiating to the back of his head. The headaches were severe when upright, and relieved by lying down. Over the next few days, he developed nausea and vomiting, and severe generalized headache. Neurological examination was normal. Screening lab work was within normal limits. CT of the head was normal. Lumbar puncture showed a low pressure of $65 \mathrm{~mm} \mathrm{H}_{2} \mathrm{O}, 725$ $\mathrm{mg} / \mathrm{L}$ of protein, no red blood cells, normal WBC count, and negative culture. MRI performed on admission, and repeated two weeks later while the patient was still symptomatic, demonstrated no evidence of CSF leakage, brain descent, or meningeal enhancement. His symptoms were managed with intravenous fluids and dimenhydrinate, and resolved with conservative management within a few weeks. 


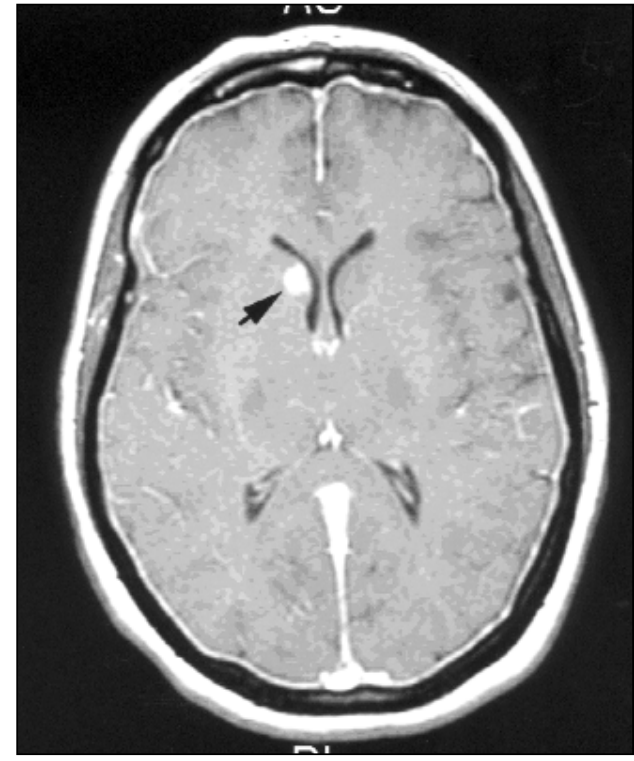

Figure 3: Gadolinium-enhanced axial MRI showing caudate lesion (Patient 3)

\section{Discussion}

The typical presentation of SIH is a triad of postural headache, low CSF pressure, and MRI abnormalities, but findings may vary significantly. Headache typically begins spontaneously, although it may be subsequent to mild trauma, vigorous exercise, ${ }^{6,7}$ or violent coughing (presumably due to disruption of the nerve root sleeve). ${ }^{8}$ The symptoms in Patient 2 may have been a result of a roller coaster ride or new yoga program. The severe, postural, and holocranial headache is similar to iatrogenic secondary intracranial hypotension after lumbar puncture. Occasionally, pain may localize to the frontal or occipital regions ${ }^{8}$ and, in some cases, may be nonpositional. ${ }^{9}$

Low CSF pressure may induce an orthostatic headache when approximately $10 \%$ of CSF volume is withdrawn, ${ }^{10}$ possibly due to two factors: (1) displacement of pain sensitive structures in the upright position by a syphoning effect, which is consistent with observed worsening with jugular venous compression and Valsalva; ${ }^{8}$ (2) displacement of dural veins producing engorgement of the meninges. MRI scanning may demonstrate the brain displacement responsible for traction, as it did in two of our cases, but this finding is minimized due to the obligatory recumbent position during scanning.

One of our patients had ataxia and facial paresthesias, suggesting brainstem, cranial nerve, or cerebellar dysfunction. Various other symptoms that have been reported in SIH include neck stiffness, photophobia, nausea, vomiting, facial weakness, ${ }^{2}$ and auditory symptoms such as sensorineural hearing loss, hyperacusis, tinnitus, vertigo ${ }^{2}$ and "popping". ${ }^{11}$ Hughson $^{12}$ suggests that auditory symptoms may be secondary to decreased CSF pressure causing a reduction in intralabyrinthine pressure and decreasing transmission of high frequency tones. Visual symptoms, such as blurred vision, and diplopia secondary to sixth nerve $\mathrm{e}^{13}$ or third nerve $\mathrm{e}^{14}$ palsies, may be a result of cranial nerve traction. ${ }^{13}$ Other unusual presentations include bradycardia, nystagmus, binasal fields defect, ${ }^{15}$ stupor secondary to diencephalic compression, ${ }^{16}$ cerebellar ataxia, bulbar weakness, and parkinsonism. ${ }^{17}$ The latter may be due to a compressive effect on the brainstem.

The second classical feature of SIH is low CSF pressure, which is typically, but not always ${ }^{18}$, less than $60 \mathrm{~mm} \mathrm{H}_{2} \mathrm{O}$. The mechanism of low CSF pressure is still uncertain, with some authors suggesting decreased CSF production ${ }^{19}$ or hyperabsorption $^{15}$ as possible mechanisms. However, recent studies implicate a dural CSF leak, which has subsequently been demonstrated by cisternography in several reported patients. ${ }^{8}$ The CSF collections in our patients may be an indication of the site of the leak. An underlying area of weakness in the dura or arachnoid along nerve root sleeves, or small meningeal defects such as spinal epidural cysts, ${ }^{20}$ may predispose a patient to leaks when accompanied by minor trauma. Moayeri ${ }^{15}$ suggests disorders affecting connective tissue, such as thyroid dysfunction or Ehlers-Danlos syndrome, may predispose to diverticula rupture by its role in the maintenance of normal connective tissue. Rarely, extradural lesions, such as a bone spur, can create a dural rent responsible for $\mathrm{SIH} .{ }^{21}$

Other CSF changes may include increased protein content and erythrocytosis. ${ }^{8}$ All of our patients who had lumbar punctures performed had protein elevation, although none demonstrated significant erythrocytosis or lymphocytic pleocytosis. A low CSF pressure state likely leads to meningeal hyperemia and diapedesis of red cells into the CSF, and may also be responsible for the passage of serum protein into the CSF. ${ }^{8}$ Lymphocytic pleocytosis may be caused by a local inflammatory reaction at the site of CSF leakage, or in response to red blood cells.

The third classic feature of SIH, diffuse pachymeningeal enhancement on MRI, is thought to be secondary to engorgement of dural bridging veins. Mokri ${ }^{2}$ found decreased CSF pressure in only $46 \%$ of patients with SIH, leading to the suggestion that MRI engorgement results from CSF hypovolemia (in accordance with the Monroe Kelly hypothesis) rather than low pressure. The pachymeninges, which have no blood brain barrier (unlike the leptomeninges), may enhance as a result of pressure gradient driven extravasation of contrast. These changes may be differentiated from inflammatory and neoplastic etiologies in which meningeal enhancement is more likely to be focally distributed, and appear as nodular or discontinuous plaques. Meningitis may be distinguished by enhancement that tends to localize in the extraxial spaces at the base of the brain. ${ }^{22}$ Biopsy of meningeal specimens have shown reactive changes only, typically demonstrating a subdural membrane of fibroblasts and small thin-walled blood vessels in an amorphous matrix or a fibrocollagenous proliferation of the leptomeninges. ${ }^{23,24}$ Meningeal enhancement tends to resolve without sequelae within a few months, as symptoms resolve. It is unclear why patient 4 failed to show any MRI changes, despite strong suspicion of SIH based on: (1) classic symptoms; (2) spontaneous resolution; and (3) low CSF pressure. Lack of meningeal enhancement in SIH has been reported in one previous case study, but it is considered a hallmark feature of the diagnosis. ${ }^{5}$

Other MRI findings may be noted, such as low lying 
cerebellar tonsils, displacement of the brainstem, effacement of the interpeduncular and prepontine cisterns, enlargement of the pituitary gland, and ventricular collapse. Subdural hematomas may result from rupture of bridging veins when the brain pulls away from the dura as the CSF volume decreases. ${ }^{25}$ Spinal MRI findings may include dural enhancement, spinal hygromas and dilatation of the anterior internal vertebral plexus. ${ }^{26}$ No previous cases have reported an asymptomatic caudate lesion such as was seen in patient 3 . It could be speculated that this was due to traction on small penetrating arteries leading to infarction. No evidence of neoplasm was found on follow-up examination. While all of our patients' symptoms and findings resolved, including the caudate lesion, occasionally they persist even with successful treatment. ${ }^{27}$

If SIH is strongly suspected, other diagnostic modalities, not employed in our cases, may be of benefit. While its sensitivity is low $(60 \%)$, radionuclide cisternography has been shown to demonstrate rapid clearance of the radioisotope from the CSF space, early appearance in the urinary bladder and possible identification of the site of leakage. ${ }^{28}$ Rando $^{8}$ suggests that CT contrast myelography may demonstrate abnormal root sleeve anatomy or cysts that may be surgically repaired, although it is difficult to examine a wide area using axial CT if the leakage site is unclear. Despite few documented cases, ${ }^{29}$ magnetic resonance myelography (cisternography), which eliminates the signal from epidural fat tissue thereby enhancing CSF signal, may be helpful to clarify the cause and site of CSF leakage. Myelography may detect an extradural collection of CSF, whereas radioisotope cisternography is more sensitive for active CSF leakage. Chen et $\mathrm{al}^{30}$ suggest engorgement of the superior ophthalmic vein on transorbital colour doppler flow imaging may correlate hemodynamically with low CSF pressure. However, the utility and availability of these imaging modalities is questionable at present.

As demonstrated by our patients, analgesics are usually of little benefit in $\mathrm{SIH}^{8}$ Reported treatments have included caffeine, intravenous fluids, ${ }^{31}$ blood patching, ${ }^{32}$ inhalation of carbon dioxide, ${ }^{32}$ intrathecal saline infusions, ${ }^{33}$ and surgery. ${ }^{34}$ Surgical options consist of ligation of a dural tear, epidural packing of leaking diverticuli (Tarlov's cysts), or repair of the underlying lesions causing these abnormalities, such as cervical bone spurs. ${ }^{21}$ While most respond to conservative treatment, as did our patients, epidural blood patching has also been found to be highly effective $\mathrm{e}^{35-37}$ by displacing and compressing the dural sac as well as "plugging the leak." Even when the site of tear (which is usually cervicothoracic ${ }^{38}$ ) is unknown, one series found 15 out of 17 patients were still treated with patching. ${ }^{39}$ The effectiveness of mineralocorticoids and glucocorticoids is uncertain. Regardless of treatment, symptoms usually resolve within two weeks but may last up to several months.

\section{CONCLUSION}

In summary, we report four cases that presented with postural headache, low CSF pressure and protein elevation, without growth on CSF culture or positive cytology. Three of the patients exhibited classic MRI findings of meningeal enhancement and fluid collections. One patient had no MRI abnormalities, despite prominent postural headache and reduced CSF pressure at lumbar puncture. All patients recovered without surgery or blood patch.
As our study supports, absence of radiological abnormalities does not exclude the diagnosis of SIH. While clinical suspicion is the most important tool, new research into other radiographic studies may prove useful in developing a definitive diagnostic study.

\section{REFERENCES}

1. Schaltenbrand G. Die akute Aliquorrhoe. Verh Dtsch Ges Inn Med 1940; 52: 473-481.

2. Mokri B, Piepgras DG, Miller GM. Syndrome of orthostatic headaches and diffuse pachymeningeal gadolinium enhancement. Mayo Clin Proc 1997; 72: 400-413.

3. Hochman SM, Naidich TP, Kobetz SA, Fernandez-Maitin A. Spontaneous intracranial hypotension with pachymeningeal enhancement on MRI. Neurology 1992; 42: 1628-1630.

4. Fishman RA, Dillon WP. Dural enhancement and cerebral displacement secondary to intracranial hypotension. Neurology 1993; 43: 609-611.

5. Schievink WI, Tourje J. Intracranial hypotension without meningeal enhancement on magnetic resonance imaging. Case report. J Neurosurg 2000; 92: 475-477.

6. Garcia-Albea E, Cabrera F, Tejeiro J, et al. Delayed post-exertional headache, intracranial hypotension, and racket sports. J Neurol Neurosurg Psychiatry 1992; 55: 975.

7. Schievink WI, Ebersold MJ, Atkinson JLD. Roller coaster headache due to spinal cerebrospinal fluid leak. Lancet 1996; 347: 1409.

8. Rando TA, Fishman RA. Spontaneous intracranial hypotension: report of two cases and review of the literature. Neurology 1992; 42: 481-487.

9. Schievink WI, Smith KA. Nonpositional headache caused by spontaneous intracranial hypotension. Neurology 1998; 51: 1768-1789.

10. Kunkle EC, Ray BS, Wolff HG. Experimental studies on headache: analysis of the headache associated with changes in intracranial pressure. Arch Neurol Psychiatry 1943; 49: 323-358.

11. Renowden SA, Gregory R, Hyman N, Hilton-Jones D. Spontaneous intracranial hypotension. J Neurol Neurosurg Psychiatry 1995; 59: $511-515$

12. Hughson W. A note on the relationship of cerebrospinal and intralabyrinthine pressures. Am J Physiol 1932; 101: 396-407.

13. Horton JC, Fishman RA. Neurovisual findings in the syndrome of spontaneous intracranial hypotension from dural cerebrospinal fluid leak. Opthalmology 1994; 101: 244-251.

14. Ferrante E, Savino A, Brioschi A, et al. Transient oculomotor cranial nerves palsy in spontaneous intracranial hypotension. J Neurosurg Sci 1998; 42: 177-179.

15. Moayeri NN, Henson JW, Schaefer PW, Zervas NT. Spinal dural enhancement on magnetic resonance imaging associated with spontaneous intracranial hypotension. Report of three cases and review of the literature. J Neurosurg 1998; 88: 912-918.

16. Pleasure SJ, Abosch A, Friedman J, et al. Spontaneous intracranial hypotension resulting in stupor caused by diencephalic compression. Neurology 1998; 50: 1854-1857.

17. Pakiam AS, Lee CL, Lang AE. Intracranial hypotension with parkinsonism, ataxia, and bulbar weakness. Arch Neurol 1999; 56: $869-872$

18. Mokri B, Hunter SF, Atkinson JLD, Piepgras DG. Orthostatic headaches caused by CSF leak but with normal CSF pressures. Neurology 1998; 51: 786-790.

19. El Gammal T, Sobol W, Wadlington VR, et al. Cerebrospinal fluid fistula: detection with MR cisternography. AJNR 1998; 19: 627631.

20. Cloward RB. Congenital spinal extradural cysts: case report with review of literature. Ann Surg 1968; 168: 851-864.

21. Vishteh AG, Schievink WI, Baskin JJ, Sonntag VKH. Cervical bone spur presenting with spontaneous intracranial hypotension. J Neurosurg 1998; 89: 483-484.

22. Brightbill TC, Goodwin RS, Ford RG. Magnetic Resonance imaging of intracranial hypotension syndrome with pathophysiological correlation. Headache 2000; 40: 292-299. 
23. Mokri B, Parisi JE, Scheithauer BW, Piepgras DG, Miller GM. Meningeal biopsy in intracranial hypotension: meningeal enhancement on MRI. Neurology 1995; 45: 1801-1807.

24. Good DC, Ghobrial M. Pathological changes associated with intracranial hypotension and meningeal enhancement on MRI. Neurology 1993; 43: 2698-2700.

25. Burkhard PR, Duff JM. Bilateral subdural hematomas following routine lumbar diskectomy. Headache 2000; 40: 480-482.

26. Yousry I, Forderreuther BM, Moriggl B. Cervical MR Imaging in Postural Headache: MR Signs and Pathophysiological Implications. AJNR 2001; 22: 1239-1250.

27. Dunbar SA, Katz NP. Failure of delayed epidural blood patching to correct persistent cranial nerve palsies. Anesth Analg 1994; 79: 806-807.

28. Benamor M, Tainturier C, Graveleau P, Pierot L. Radionuclide cisternography in spontaneous intracranial hypotension. Clin Nucl Med 1998; 23: 150-151.

29. Matsumura A, Anno I, Kimura H, Ishikawa E, Nose T. Diagnosis of spontaneous intracranial hypotension by using magnetic resonance myelography: case report. J Neurosurg 2000; 92: 873-876.

30. Chen CC, Luo CL, Wang SJ, et al. Colour doppler imaging for diagnosis of intracranial hypotension. Lancet 1999; 354: 826-829.
31. Copobianco DJ, Kuczler FJ. Case report: primary intracranial hypotension. Milit Med 1990; 155: 64-66.

32. Gaukroger PB, Brownridge P. Epidural blood patch in the treatment of spontaneous low CSF pressure headache. Pain 1987;29:119-122.

33. Gibson BE, Wedel DJ, Faust RJ, Petersen RC. Continuous epidural saline infusion for the treatment of low CSF pressure headache. Anesthesiology 1988; 68: 789-791.

34. Schievink WI, Morreale VM, Atkinson JLD, et al. Surgical treatment of spontaneous spinal cerebrospinal fluid leaks. J Neurosurg 1998; 88: 243-246.

35. Szeinfeld M, Ihmeidan IH, Moser MM, et al. Epidural blood patch: evaluation of the volume and spread of blood injected into the epidural space. Anesthesiology 1986; 64: 820-822.

36. Weitz SR, Drasner K. Spontaneous intracranial hypotension: a series. Anesthesiology 1996; 85: 923-925.

37. Rupp SM, Wilson CB. Treatment of spontaneous cerebrospinal fluid leak with epidural blood patch. J Neurosurg 1989; 70: 808-810.

38. Schievink WI, Meyer FB, Atkinson JLD, Mokri B. Spontaneous cerebrospinal fluid leaks and intracranial hypotension. J Neurosurg 1996; 84: 598-605.

39. Fishman RA, Dillon WP. Intracranial hypotension. J Neurosurg 1997; 86: 165 . 